\title{
ESCRITA, FOTOGRAFIA E MEMÓRIA EM THE SHADOW LINES, DE Amitav GHosh
}

\section{Eliana Lourenço de Lima Reis*}

Resumo: Os romances de Amitav Ghosh se valem frequentemente do diálogo com outras midias, em especial com a fotografia. Em The shadow lines (1988), fotos são utilizadas como técnica mnemônica para facilitar a evocação das memórias da família do narrador, que procura compreender eventos traumáticos do passado, bem como para refletir sobre o significado social e histórico dessa mídia. Essas fotos são descritas em forma de écfrases que contribuem para o desenvolvimento do enredo, articulando os diversos fios narrativos.

Palavras-chave: Fotografia. Memória. Amitav Ghosh.

O

s romances do escritor indiano Amitav Ghosh se caracterizam por sua relação estreita com as mídias visuais, em especial com a pintura e a fotografia. Enquanto sua trilogia sobre a Guerra do Ópio privilegia a pintura e os pintores (sobretudo River of smoke, de 2011), The shadow lines (lançado em 1988) se vale da fotografia para expor os esforços do narrador para reconstruir seu passado a fim de compreender um acontecimento traumático que marcou sua infância: a morte, aos 29 anos, de seu primo Tridib, visto como amigo e mentor, durante um dos muitos episódios de violência entre hindus e muçulmanos no subcontinente indiano.

O romance se passa em locais e tempos diversos, que, de alguma forma, se espelham: Londres, durante a Segunda Guerra Mundial; Délhi e Calcutá (na Índia), bem como Dakha (Bangladesh), durante as décadas de 1960 e 1970; e, finalmente, Londres nos anos 1980. Essa multiplicidade espacial e temporal explica, em parte, a complexidade de uma narrativa que inclui um grande número de histórias inter-relacionadas, acontecidas em locais e periodos históricos diversos, cujo impacto se faz sentir até o presente. O método narrativo é

* Universidade Federal de Minas Gerais (UFMG) - Belo Horizonte - MG - Brasil. E-mail: elianalourenco@terra.com.br 
claramente inspirado em Proust, tanto na escolha de um narrador não nomeado quanto na forma de tratar o tempo. Na verdade, Ghosh reconhece seu débito a Proust "nas maneiras como o tempo e o espaço se dissolvem na narrativa de The shadow lines" (HAWLEY, 2005, p. 8-9). O autor acrescenta que, no momento da escrita do romance, "sua ambição era fazer com o espaço o que Proust havia feito com o tempo: isto é, tornar instâncias completamente diferentes de um continuum imanentes umas às outras" (HAWLEY, 2005, p. 8-9) ${ }^{1}$. Como consequência, os personagens entram e saem da narrativa em diferentes tempos e lugares, contando suas histórias, que são, então, incorporadas à narrativa, frequentemente entrelaçadas a imagens verbais em forma de écfrases de fotografias cuja presença no romance é apenas verbal.

A fotografia, assim, cumpre um papel importante tanto no enfoque eminentemente visual das cenas e lembranças, quanto como uma das maneiras de organizar e desenvolver a narrativa. Em ambos os casos, observa-se a utilização de referências intermidiáticas, que Irina Rajewsky (2013, p. 23) define como "estratégias de constituição de sentido que contribuem para a significação total do produto de mídia”, já que este tematiza, evoca ou imita elementos ou estruturas de outra mídia convencionalmente distinta por meio da utilização de recursos específicos daquela mídia. Desse modo, apenas uma mídia (a mídia verbal escrita) está realmente presente, pois o texto que lemos é composto de modo a criar a ilusão de que estamos diante de uma outra "presença visual" (RAJEWSKY, 2013, p. 26), isto é, uma fotografia. Assim, existe um cruzamento de fronteiras entre as mídias por meio da evocação da fotografia pela literatura. Porém, o romance explora também um outro tipo de cruzamento intermidiático: as écfrases de imagens fotográficas (provavelmente fictícias) utilizadas com finalidade narrativa, que constituem a transposição de um texto não verbal para um texto verbal. Como propõe Claus Clüver (no prelo) em um texto recente, "[a] écfrase é a representação verbal de configurações reais ou fictícias compostas em uma mídia visual não cinética".

Por se tratar de leituras pessoais de imagens visuais, as narrativas de cenas captadas em fotografias não pretendem apresentar a verdade, ou seja, o que realmente teria acontecido no passado. Uma das lições que o narrador aprende com seu primo Tridib é justamente saber usar bem a imaginação: "entre outras coisas, Tridib era um arqueólogo; ele não estava interessado em reinos encantados: a única coisa que ele queria me ensinar, ele costumava dizer, era usar a imaginação com precisão" ${ }^{2}$ (GHOSH, 2005, p. 24). Ou seja, seria preciso trabalhar como um arqueólogo que, a partir de fragmentos e ruínas, consegue imaginar e recriar o passado "com precisão", baseando-se na interpretação de evidências para criar uma narrativa. Isso significa, em última análise, aprender a ver com os próprios olhos para, então, dar nova vida até mesmo ao que não se presenciou diretamente. Tridib dizia que "não era possivel ver sem inventar o que se viu, por isso devíamos ao menos tentar fazer isso corretamente", pois "a alternativa não seria o vazio - significava apenas que, se não tentássemos, nun-

\footnotetext{
No original: "in the ways in which time and space are collapsed in the narrative of The Shadow Lines. I remember that at the time my ambition was to do with space what Proust had done with time: that is, to make completely different instances of a continuum immanent in each other". Todas as traduções foram feitas pelo autor deste artigo.

2 No original: "among other things, Tridib was an archaeologist; he was not interested in fairylands: the one thing he wanted to teach me, he used to say, was to use my imagination with precision".
} 
ca estariamos livres das invenções de outras pessoas"3 (GHOSH, 2005, p. 31). Essa habilidade confere ao narrador a capacidade de interpretar os signos verbais e visuais a fim de não só imaginar cenas ou locais que conhece apenas por meio de relatos alheios, mas também poder traduzir fotografias em narrativas verbais reimaginadas "com precisão". Essa importância da imaginação traz para o centro da discussão, por um lado, a capacidade criativa e o poder da arte de convocar a "verdade", e, por outro, o caráter individual da leitura da realidade, seja ela fruto da experiência pessoal, seja da experiência alheia incorporada por meio de imagens ou relatos.

Essa atitude pode ser compreendida à luz das reflexões sobre a fotografia, apresentadas por Susan Sontag (1977, p. 23), que observa que "qualquer fotografia tem significados múltiplos", pois

[a] sabedoria fundamental da imagem fotográfica é dizer: "existe a superfície. Agora pense - ou melhor, sinta, intua - o que está mais além, como a realidade deve ser quando tem essa aparência". As fotografias, que em si mesmas não podem explicar coisa alguma, são convites inesgotáveis à dedução, especulação e fantasia 4 .

Por serem ao mesmo tempo "uma pseudopresença e um sinal de ausência", as fotografias, principalmente as relacionadas ao passado distante ou a locais longínquos, constituem "incitações ao devaneio" e "expressam uma sensação que é tanto sentimental quanto implicitamente mágica: elas são tentativas de entrar em contato ou de reivindicar outra realidade"5 (SONTAG, 1977, p. 16). Desse modo, as imagens fotográficas utilizadas em The shadow lines não são percebidas como signos icônicos - isto é, aqueles que guardam uma relação de semelhança com o referente -, mas como índices que apontam para uma realidade a ser recriada por meio da imaginação individual, como queria Tridib. As fotos, então, constituem gatilhos para a memória (até mesmo para a memória alheia) e para a recriação ficcional do que poderia ter acontecido, filtrado pelo olhar do narrador, que frequentemente percebe uma realidade que diverge daquela proposta pelos personagens retratados.

Esse processo pode ser verificado, por exemplo, nas passagens em que o narrador rememora sua percepção das fotos contidas nos anuários das escolas internacionais que a prima Ila frequentava ao acompanhar o pai diplomata em missões ao redor do mundo. A cada visita à Índia, a família exibia artefatos levados como suvenires do país em que haviam morado; porém, para Ila, o que contava eram apenas as imagens nos anuários, que ela utilizava para relatar suas experiências ao narrador, que acaba por sentir pelas publicações a mesma atração que elas exerciam sobre a prima. As fotos apresentavam um mundo diferente: escolas frequentadas por meninos e meninas juntos, sem uniformes, cujos rostos revelam uma diversidade étnica surpreendente e que, muitas vezes,

3 No original: "we could not see without inventing what we saw, so at least we could try to do it properly [...] because the alternative wasn't blankness - it only meant that if we didn't try ourselves, we would never be free of other people's inventions".

4 No original: "any photograph has multiple meanings. [...] The ultimate wisdom of the photographic image is to say: 'there is the surface. Now think - or rather feel, intuit - what is beyond it, what the reality must be like if it looks this way.' Photographs, which cannot themselves explain anything, are inexhaustible invitations to deduction, speculation, and fantasy".

5 No original: "A photograph is both a pseudo-presence and a token of absence. Like a wood fire in a room, photographs - especially those of people, of distant landscapes and faraway cities, of the vanished past, are incitements to reverie. [....] all such talismanic uses of photography express a feeling both sentimental and implicitly magical: they are attempts to contact or lay claim to another reality". 
reapareciam em outra escola internacional no ano seguinte. Ila falava sobre suas amigas e namorados, discorrendo sobre festas e passeios, mas o narrador percebe uma disparidade entre as histórias criadas por Ila e o que as fotos lhe revelam. Ila interpreta as imagens conforme seu desejo e não como ela as vivenciou, pois sua leitura constitui a única forma de que ela dispõe para se mostrar como gostaria de ser, e não como a estrangeira deslocada que o primo percebe nos retratos dos quais ela se encontra ausente ou é apenas uma figura ao fundo, em segundo plano (GHOSH, 2005, p. 22-23). Se, para Ila, as fotos funcionam como um convite à fantasia compensatória, para o narrador, elas constituem "convites à dedução e especulação", ao trabalho da imaginação recriadora.

Além de servir como estratégia narrativa, a mídia fotografia como prática social histórica é também tematizada e se torna objeto de reflexão. Uma dessas ocorrências pode ser observada em um trecho do romance em que o narrador descreve uma imagem que Tridib lhe havia mostrado muitos anos antes, ao contar as histórias individuais de cada um dos rapazes retratados em uma foto feita às vésperas da Segunda Guerra Mundial:

Há algo surpreendentemente diferente na qualidade das fotografias daquela época. Não tem nada a ver com o envelhecimento ou a cor, ou mesmo com o toque do papel. [...]. Tem a ver com o modo como a câmera olhava para as pessoas naquela época.

Nas fotos de família modernas a câmera finge circular como um amigo, clicando naqueles momentos em que seus sujeitos se desarranjaram a fim de apresentar para a câmara as poses que eles imaginam como informais. Porém, nos retratos daquela época, a câmara é ainda um olho público e estrangeiro, frente ao qual as pessoas se sentem inclinadas a desafiar a intrusão ao fazer poses de hilaridade provocadora, ou então a demonstrar compostura na expressão e a endireitar os ombros, nem sempre formalmente, mas em geral com aquela dose de rigidez suficiente para sugerir uma face pública"6 (GHOSH, 2005, p. 59).

Esse retrato foi tirado pelo pai de Tridib, com sua câmara comprada recentemente, e mostra um grupo de jovens no quintal de uma casa em Londres. Nesse trecho específico do romance, a fotografia é evocada por meio não apenas de suas técnicas, mas também da discussão do significado que cada momento histórico atribui a essa mídia, em especial ao subsistema de retratos relacionados à vida privada e às convenções a serem seguidas. Isto é, no presente da narrativa, o fotógrafo espera até conseguir captar uma pose "informal", que supostamente representa a vida privada; no passado, buscava-se uma "segurança desafiadora" ou então a compostura - em ambos os casos, a câmara raramente apanha o sujeito de surpresa. O narrador imagina as circunstâncias da foto: o fotógrafo (o tio do narrador) observando a cena e esperando a pose certa; o riso dos jovens, de pé ao lado do que "parece um canteiro de flores em desalinho"7 (GHOSH, 2005, p. 59), mas que, na realidade, se trata da construção de um abrigo antiaéreo:

6 No original: "There is something strikingly different about the quality of photographs of that time. It has nothing to do with age or color, or the feel of the paper. [...] It has to do with the way the camera looked at people then. I In modern family photographs the camera pretends to circulate like a friend, clicking its shutters at those moments when its subjects have disarranged themselves to present to it those postures which they like to think of as informal. But in the pictures of that time the camera is still a public and alien eye faced with which people feel bound either to challenge the intrusion by striking postures of defiant hilarity, or else to compose their faces and straighten their shoulders, not always formally, but usually with just that hint of stiffness which is enough to suggest a public face".

7 No original: "it looks like a dishevelled flowerbed". 
Talvez, momentos antes de o retrato ser tirado, eles estivessem morrendo de rir ao olhar para esse futuro abrigo patético. Mas agora que a câmera está voltada para eles, apenas um está rindo, desafiando a lente. Os restantes já recompuseram a expressão ${ }^{8}$ (GHOSH, 2005, p. 59).

Esse parágrafo é seguido por uma écfrase dessa foto, descrevendo a aparência e a atitude de cada um dos rapazes que nela aparecem, bem como suas histórias. O relato se torna, então, o que W. J. T. Mitchell (1995, p. 271-272) denomina um "retrato textual" ou um "texto-imagem", resultante da colaboração entre a imagem e a palavra escrita. Nesse caso, o retrato existe apenas nas palavras utilizadas pelo narrador para descrevê-lo e em sua reação a ele, bem como na rememoração do que o tio havia contado muitos anos antes.

"A fotografia é uma fina fatia do espaço e também do tempo", observa Susan Sontag (1977, p. 22). É exatamente esse tempo-espaço que o narrador busca captar em sua exploração de um mundo desaparecido: em 1939, parecia existir "um tipo de animação", que tornava as pessoas mais "amáveis", o que explicaria por que a mãe de Tridib afirma "ter tido muita sorte" de poder "observar a Inglaterra reviver"10 (GHOSH, 2005, p. 65). O público e o privado se juntam nesse retrato verbal de uma Inglaterra que desapareceu para sempre, juntamente com os jovens cujas histórias conhecemos. Essas histórias adquirem uma pungência mais profunda diante de sua premonição do fim não só daquela época histórica, mas também dos próprios indivíduos retratados:

[...] eles sabiam, todos os quatro, que seu mundo e, muito provavelmente, eles mesmos, não sobreviveriam à guerra. Qual é a cor desse conhecimento? Ninguém sabe, ninguém jamais poderá saber, nem mesmo na memória, pois há momentos no tempo que não são conhecíveis: ninguém pode saber como era ser jovem e inteligente no verão de 1939 em Londres ou Berlim ${ }^{11}$ (GHOSH, 2005, p. 66-67).

É interessante notar como essas frases ecoam a definição da fotografia como memento mori (lembra que és mortal) por Susan Sontag (1977, p. 22) e, mais tarde, por Roland Barthes (1984), pois ambos realçam a associação entre a fotografia, a morte e a imortalidade. Para Sontag (1977, p. 70),

A fotografia é o inventário da mortalidade. Um toque de dedo agora é suficiente para emprestar a um momento uma ironia póstuma. Fotografias mostram as pessoas tão irrefutavelmente lá e numa idade especifica de suas vidas; [...]. As fotografias declaram a inocência, a vulnerabilidade de vidas a caminho de sua própria destruição, e essa ligação entre a fotografia e a morte assombra as fotografias de pessoas ${ }^{12}$.

8 No original: "Perhaps moments before the picture was taken they were doubled up with laughter, looking down at this pathetic would-be shelter. But now that the camera is upon them only one of them is laughing, defying the lens. The rest have composed their faces".

9 No original: "The photograph is a thin slice of space as well as time".

10 No original: "there is a kind of exhilaration in the air. [...] I've been lucky, I've been able to watch England coming alive".

11 No original: "[...] they knew, all four of them, that their world, and in all probability they themselves, would not survive the war. What is the colour of that knowledge? Nobody knows, nobody can ever know, not even in memory, because there are moments in time that are not knowable: nobody can ever know what it was like to be young and intelligent in the summer of 1939 in London or Berlin".

12 No original: "Photography is the inventory of mortality. A touch of the finger now suffices to invest a moment with posthumous irony. Photographs show people being so irrefutably there and at a specific age in their lives; [...]. Photographs state the innocence, the vulnerability of lives heading toward their own destruction, and this link between photography and death haunts of photographs of people". 
É exatamente esse paradoxo característico da fotografia - um índice tanto da mortalidade quanto da imortalidade - que o narrador de The shadow lines percebe, pois, por um lado, como observa Roland Barthes (1984, p. 129), "[t]oda fotografia é um atestado de presença", "uma emanação do real passado", já que seu "poder de autenticação sobrepõe-se ao poder de representação" (p. 132). "Isso-foi" é a característica básica da fotografia, seu noema, segundo Barthes (1984, p. 115), pois ela "repete mecanicamente o que nunca mais poderá repetir-se existencialmente" (p. 13). Por outro lado, cada fotografia conta duas histórias ao mesmo tempo: a história de seu passado e de como ele foi recuperado pelo observador. Nesse romance, é o narrador que, a partir de seu presente, lê naquela imagem fotográfica o antes e o depois do "instante decisivo" que fixa o movimento, um gesto ou um olhar, já conhecendo o caminho inexorável daqueles jovens em direção à morte durante a guerra. Contudo, apesar de todo esforço para evocar o passado por meio da fotografia como técnica mnemônica e da empatia que pode ligar os sujeitos, a experiência do outro é irrecuperável, pois, como alerta o narrador, "há momentos no tempo que não são conhecíveis" (GHOSH, 2005, p. 66-67), indicando um limite para toda tentativa de recuperar o passado alheio.

"Uma fotografia é tanto uma pseudopresença quanto um sinal de ausência", Susan Sontag (1977, p. 16) observa; por meio dela, pode-se buscar "entrar em contato ou reivindicar outra realidade"13 - algo que ocorre em The shadow lines. Nesse romance, as fotografias funcionam como uma espécie de ímã que atrai e junta as histórias e experiências dos diferentes personagens, que são, então, reimaginadas pelo narrador, cuja história constitui o resultado da absorção e incorporação de vozes e pontos de vista diversos. Embora alguns momentos permaneçam "não conheciveis" e impossiveis de traduzir, ainda parece possivel registrar esses traços ou restos, bem como tentar "visualizar o invisivel" ${ }^{14}$ (SCHMITZ-EMANS, 2010, p. 111): os espectros ou emanações das experiências de outras pessoas, ou seja, as sombras que eles lançam sobre o presente, como sugere o título do romance.

O crítico John Berger (1980, p. 293) afirma que "se aprende a ler fotografias como se aprende a ler pegadas ou cardiogramas. [...] O que é mostrado invoca o que não o é"15. E como seria possivel ler o que não é mostrado? Por meio do que Kaja Silverman (apud HIRSCH, 1997, p. 273) denomina uma "recordação heteropática", isto é, por meio da capacidade que o eu tem "de assumir a memória dos outros [...] por meio de um processo de identificação heteropática"16. Ou, então, por meio de uma "pós-memória", um conceito criado por Marianne Hirsch (1997, p. 13) para se referir à memória "postergada, indireta, secundária" dos filhos dos sobreviventes da Shoah, cujo vínculo com o passado se distingue da memória no sentido comum do termo devido à distância entre gerações e a história. Assim, uma pós-memória é “mediada pelo pai-sobrevivente, mas determi-

\footnotetext{
13 No original: "A photograph is both a pseudo-presence and a token of absence.[...] they are attempts to contact or lay claim to another reality".

14 No original: "the idea of photo-graphy [sic] as a medium visualizing the invisible".

15 No original: "One learns to read photographs as one learns to read footprints or cardiograms. [...] What is shown invokes what is not shown".

16 No original: "heteropathic recollection [...] the self's ability to take on the memory of others, even culturally devalued others,
} through a process of heteropathic identification". 
nante para o filho"17 e baseada não apenas no testemunho oral do pai, mas também em fotos e outros itens pessoais que constituem indices de outras vidas. A pós-memória, então, é alimentada não apenas pela lembrança, mas também pela imaginação. No caso do narrador de The shadow lines, o evento traumático não é a Shoah, mas seu equivalente na Índia: a violência sectária, endêmica no subcontinente indiano desde a Partição, na época de sua Independência, em 1947, que é responsável também pela morte do primo do narrador, ocorrida durante um distúrbio em Dhakha (atualmente capital de Bangladesh). Como o jovem que mergulha no Ganges, apresentado na foto que compõe a capa do livro, o narrador mergulha nos restos indéxicos de seu passado, tais como as fotos ou relatos de família, a fim de compreender as circunstâncias de sua morte - que ele, juntamente com o leitor, só vem a conhecer na parte final do romance. Entretanto, em contraste com o estilo representativo realista e extremamente visual ao longo do livro, os momentos finais de Tridib só podem ser contados por uma das testemunhas (Robi) em forma de um pesadelo que o assombra, apontando para a dificuldade de verbalizar uma experiência traumática (GHOSH, 2005, p. 238-241). Contudo, é apenas algumas páginas depois desse relato que o leitor (juntamente com o narrador) compreende o acontecimento em toda sua complexidade, quando outra testemunha (May, uma amiga inglesa da família) confessa que, embora indiretamente, ela pode ser em parte responsável pela morte de Tridib, que teria se arriscado para salvá-la.

Ao passo que as imagens-textos inspiradas pelas fotos e as histórias (ou mitos) de família servem para recriar o mundo de personagens diferentes em diversos tempos e espaços, o evento traumático em si é contado em uma narrativa marcada por distorções, disfarçada em um sonho recorrente, exigindo do leitor um esforço para construir uma imagem visual da cena. Não se pode "fotografar" a dor e o trauma, ou representá-los de modo realista: é o que o romance parece sugerir. A única forma de abordar essas experiências é "de maneira oblíqua, tangencial, por meio da referência, e não da confrontação direta" 18 com o horror, como observa Adriana Cavarero (2015, p. 6), citando W. D. Sebald, cujos interlocutores são todos "contadores relutantes"19, como Robi em seu relato onírico da morte de Tridib. Assim, para se construir uma versão "verdadeira" sobre o passado familiar e coletivo, é necessário saber ler os fragmentos visuais e narrativos de olhares e vozes diversos em termos temporais e espaciais, por meio de um relato que articule o público e o privado, o arquivo verbal e o fotográfico.

\section{Writing, Photography and memory in Amitav Ghosh's The shadow lines}

Abstract: A dialogue with different media, especially photography, characterizes many of Amitav Ghosh's novels. In The shadow lines (1988), pictures are used as mnemonic devices in the narrator's attempt to recover his family's past, marked by traumatic experiences with which he tries to come to terms. These photographs not only contribute to the development of the plot in the form of ekphra-

\footnotetext{
17 No original: "postmemory [...] the delayed, indirect, secondary memory [...] mediated by the father-survivor but determinative for the son".

18 No original: "the only way in which one can approach these things, in my view, is obliquely, tangentially, by reference rather than by direct confrontation".

19 No original: "reluctant tellers".
} 
ses that articulate the action taking place in different times and spaces, but also to a reflection about the social and historical significance of the medium.

Keywords: Photography. Memory. Amitav Ghosh.

\section{REFERÊNCIAS}

BARTHES, R. A câmara clara: nota sobre a fotografia. Tradução Júlio Castañon Guimarães. Rio de Janeiro: Nova Fronteira, 1984.

BERGER, J. Understanding a photograph. In: TRACHTENBERG, A. (Ed.). Classic essays on photography. New Haven, CT: Leete's Island Books, 1980. p. 291-297.

CAVARERO, A. Narrative against destruction. New Literary History, v. 46, n. 1, p. 1-16, 2015.

CLÜVER, C. Écfrase e adaptação: casos de transposição intermidiática? No prelo.

GHOSH, A. The shadow lines. Boston; New York: Mariner, 2005.

GHOSH, A. River of smoke. New York: Picador, 2011.

HAWLEY, J. C. Amitav Ghosh: an introduction. New Delhi: Foundation Books, 2005.

HIRSCH, M. Family frames: photography, narrative and postmemory. Cambridge: Harvard University Press, 1997.

MITCHELL, W. J. T. Picture theory: essays on verbal and visual representation. Chicago: University of Chicago Press, 1995.

RAJEWSKY, I. Intermidialidade, intertextualidade e "remediação": uma perspectiva literária sobre a intermidialidade. Tradução Thais F. N. Diniz e Eliana Lourenço de L. Reis. In: DINIZ, T. F. N. (Org.). Intermidialidade e estudos interartes: desafios da arte contemporânea. Belo Horizonte: Editora UFMG, 2013. v. 1, p. $15-45$.

SCHMITZ-EMANS, M. "A la recherche de la réalité perdue": ambiguous alliances between literature and photography. In: BARON, C.; ENGEL, M. (Ed.). Realism/ anti-realism in 20th-century literature. Amsterdam: Rodopi, 2010. p. 105-125. SONTAG, S. On photography. New York: Picador, 1977.

Recebido em dezembro de 2016. Aprovado em janeiro de 2017. 